\title{
STRUCTURAL ANALYSIS OF STEEL-CONCRETE COMPOSITE BEAM BRIDGES UTILIZING THE SHEAR CONNECTION MODEL
}

\author{
Phung Ba Thang*, Lai Van Anh \\ University of Transport Technology, 54 Trieu Khuc, Thanh Xuan, Hanoi, 100000, Vietnam
}

\author{
ARTICLE INFO \\ TYPE: Research Article \\ Received: 11/01/2021 \\ Revised: 07/09/2021 \\ Accepted: 14/9/2021 \\ Published online: 15/09/2021 \\ https://doi.org/10.47869/tcsj.72.7.4 \\ * Corresponding author \\ Email: thangpb@utt.edu.vn; Tel: +84912373712
}

\begin{abstract}
Shear connector (typically shear studs) plays a vital role as a transfer zone between steel and concrete in steel-concrete composite bridge girder. In the previous studies, the connection between steel beam and reinforced concrete slab were considered as continuous joint. However, in practice, this connection is discrete, which allows the slipping and peeling phenomenon between two layers (the influence of peeling is usually very small and could be ignored). To reflect this actual working mechanism, this study proposed a model of shear connection in the form of discrete points at the actual positions of studs for structural analysis. The model was simulated utilizing Timoshenko beam theory considering transverse shear effects. The numerical applications are carried out in order to compare two types of connections. The obtained results indicated that the proposed model properly reflected the actual performance of the structure and in some necessary cases, we should consider discrete connection for more accurate local results.
\end{abstract}

Keywords: Steel-concrete composite beam bridges, Shear connection, Euler-Bernoulli theory, Timoshenko beam theory.

(C) 2021 University of Transport and Communications

\section{INTRODUCTION}

The steel-concrete composite bridge is a flexible combination of two material including steel and concrete [1-3]. In this structure, the advantages of the high tensile strength of steel materials and high compressive strength of concrete materials are combined and work 
together via shear connectors $[1,4]$. The mechanical behaviour of the steel-concrete composite bridge strongly depends on the behaviour of shear connector. Thus, properly analysing the working mechanism of shear connector is a critical and meaningful task for evaluating the working performance of the steel-concrete composite bridge [5,6].

Generally, the steel and concrete layers are often linked utilizing connectors such as shear studs or nails [1]. Several phenomena such as slip and uplift can appear interface zone, while the uplift is significant small [7,8]. Interlayer slip affects strongly the behaviour of the steel-concrete composite bridge design and needs to be considered. This phenomenon is called partial interaction, a crucial matter in composite structure $[9,10]$. In addition, a composite beam consist of partial interaction has a greater deflection compared to that of the beam with full interaction due to a reduction of composite action and stiffness of composite beams. It is therefore unsafe to overlook the impact of interface slip on the deflection of composite beams with partial interaction [11-13].

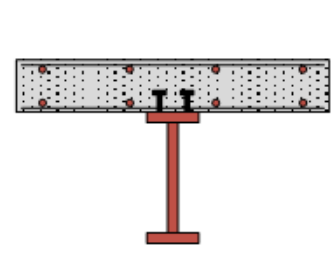

$\mathrm{A}-\mathrm{A}$

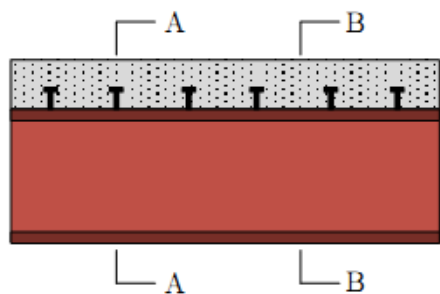

(a) composite steel concrete beam

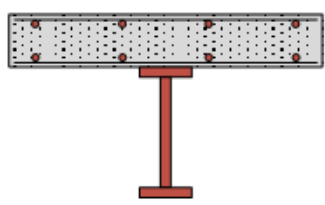

B-B

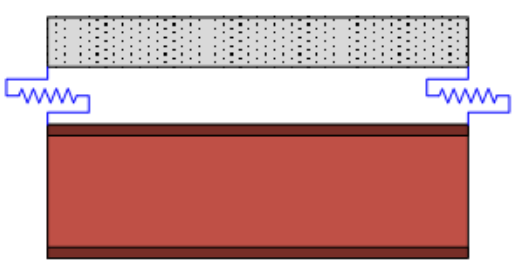

(b) discrete bond model

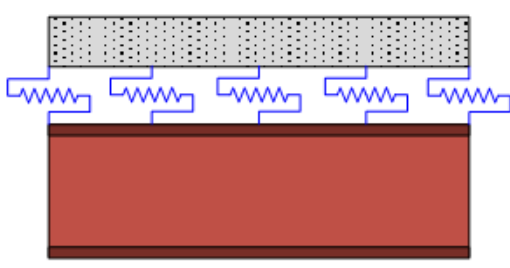

(c) distributed bond model

Figure 1. Bond models.

Over the past several decades, numerous analytical and numerical models characterized by different levels of approximation have been proposed in the literature [8,14-16]. The first formulation has been proposed for the geometrically linear analysis of elastic composite beams with partial interaction is commonly attributed to Newmark et al. [14]. They adopted the Euler-Bernoulli kinematic assumptions for both the concrete slab and the steel profile and considered a continuous and linear relationship between the relative interface displacements (continuous bond) and the corresponding interface shear stresses. The model was then developed by some researcher to formulate theoretical models for the static response of composite beams in the linear elastic [8,15,16] . Recently, Saje et al. [17] developed a finite element formulation for non-linear analysis of two-layer composite planar frames with an interlayer slip. It is assumed that the beam components obey the non-linear Reissner's beam theory. Schnabl et al. [18] propose a new locking-free strain based finite element formulation based on Timoshenko's beam theory for the linear static analysis of two-layer composite beam in partial shear interaction. A new analytical solution is presented for the analysis of the geometrically and materially linear two-layer beams with interlayer slip [19]. The application of the proposed method is illustrated in a simply supported beam with uniform load. 
It can be found in the literature that the mechanical shear connection is modelled by adopting either the concentrated springs at connector locations (namely discrete bond model) or the distributed springs (namely continuous bond model, Fig. 1b). Indeed, the discrete bond model seems to describe the true nature of the connection of the usual two-layer beams (Fig. 1c). However, it requires a large number of elements, especially in the case of dense connection. Only a few authors have considered the discrete bond model to analyse the behaviour of composite beam [20]. Therefore, the objective of this paper is to simulate the behaviour of composite beams using two kind of bond in which the discrete bond model can reflect the actual performance of the structure.

\section{BASICS EQUATIONS}

As a matter of principle, the behaviour of a deformable body must satisfy three basics conditions consist of compatibility, equilibrium, and material constitutive laws (forcedeformation relation)

The following assumptions are introduced in this study:

- Euler-Bernoulli's kinematic assumptions hold for concrete slab and Timoshenko's ones apply to steel joist; therefore, both layers do not have the same rotation and curvature.

- All displacements and strains are small, so that the following models can be formulated in the linear-geometric analysis.

- Slip can occur at the slab/joist interface but no transverse separation, i.e., two layers have the same transverse displacement.

- The interface steel-concrete connection is modeled by the spring elements (discrete/continuous). All variables subscripted with "c" belong to the concrete slab section and those with "s" belong to the steel beam. The quantities with "st" and "sc" are associated with the discrete and distributed bond, respectively.

\subsection{Compatibility}

Figure 2 shows the model of the steel-concrete composite girder bridge. The EulerBernoulli theory is employed for the above concrete slab due to its small thickness, whereas the Timoshenko theory (considering the horizontal shear strain) is applied for the steel girder.

Based on the above assumptions, the axial, shear, and flexural (curvature) deformations at any sections are related to the beam displacements as follows:

$$
\begin{aligned}
& \varepsilon_{i}=\frac{d u_{i}}{d x} \quad(i=s, c) \\
& \gamma_{s}=\frac{d v}{d x}-\theta_{s} \\
& \kappa_{c}=\frac{d v^{2}}{d x} \\
& \kappa_{s}=\frac{d \theta_{s}}{d x}
\end{aligned}
$$

where $\varepsilon_{i}$ and $u_{i}$ are the axial strain component and the longitudinal displacement at the reference axis of layer $i$, respectively; $\gamma_{s}$ is the strain of layer $i, v$ is the transverse 
displacement, $\theta_{s}$ and $\kappa_{i}$ are the cross-section rotation and the curvature of layer $i$, respectively; $d_{s c}$ is the interlayer slip along the interface; $h_{i}(i=s, c)$ is the distance from the neutral axis of layer $i$ to the slab bottom.

$$
d_{s c}=u_{c}-u_{s}+h_{c} \theta_{c}+h_{s} \theta_{s}
$$

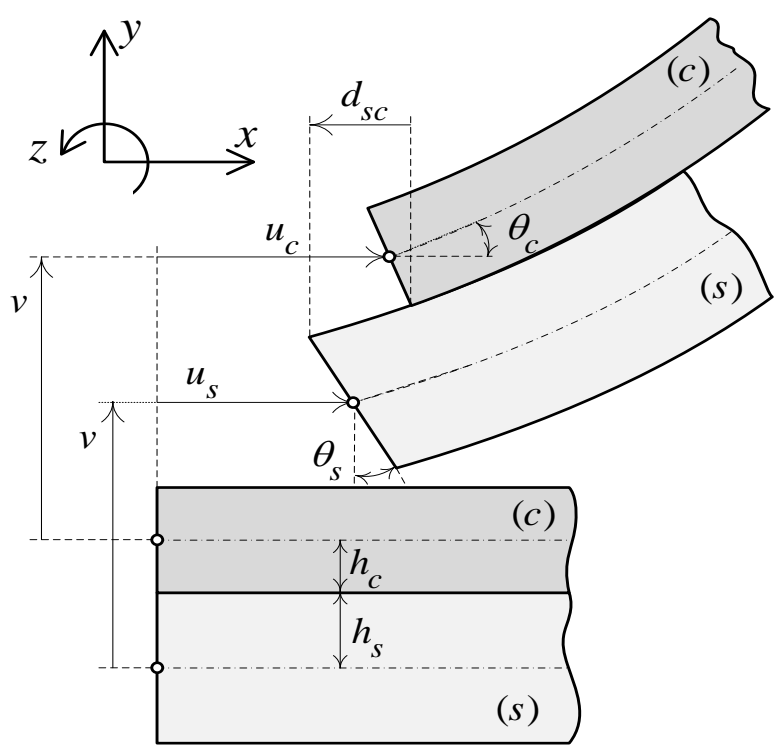

Figure 2. Kinematics of a shear deformable two-layer beam.

\subsection{Equilibrium}

- Equilibrium equations in case of distributed bond

A free body diagram of a differential element of composite beam subjected to a distributed transverse load $p_{y}$ is considered (see Fig. 3). For the element to be in equilibrium, the following equations must be satisfied:

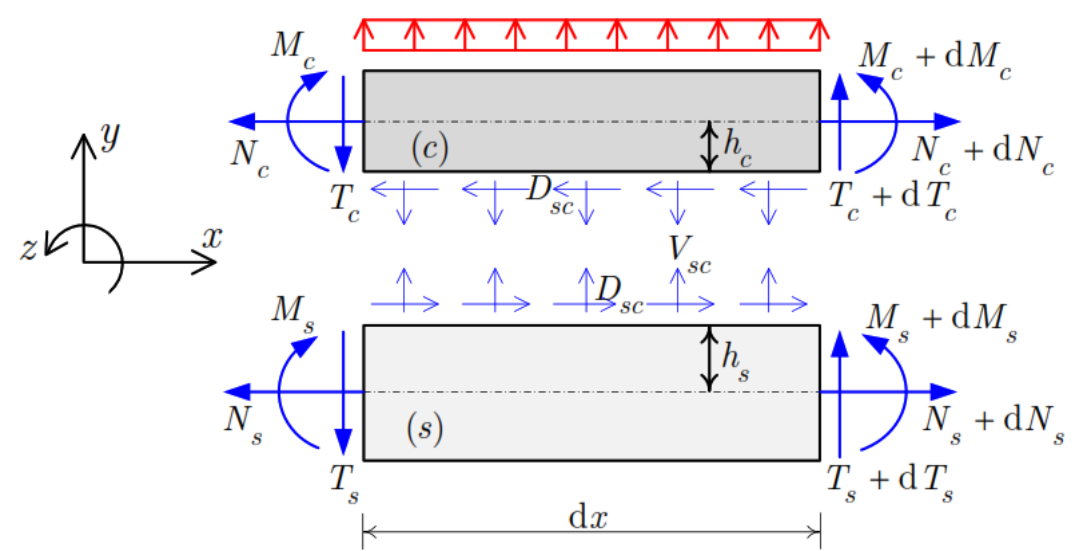

Figure 3. Composite beam segment with distributed bond.

For the steel layer: 
Transport and Communications Science Journal, Vol. 72, Issue 7 (09/2021), 811-823

$$
\begin{aligned}
& D_{s c}+\frac{d N_{s}}{d x}=0 \\
& V_{s c}+\frac{d T_{s}}{d x}=0 \\
& \frac{d M_{s}}{d x}+T_{s}-h_{s} D_{s c}=0
\end{aligned}
$$

For the concrete layer:

$$
\begin{aligned}
& \frac{d N_{c}}{d x}-D_{s c}=0 \\
& \frac{d T_{c}}{d x}+p_{y}-V_{s c}=0 \\
& \frac{d M_{c}}{d x}+T_{c}-h_{c} D_{s c}=0
\end{aligned}
$$

where $N_{i}, T_{i}, M_{i}$ (i=s, c) are the axial forces, the shear forces and bending moments acting in layer i (steel beam or concrete slab). $D_{s c}$ is the longitudinal bond force and $V_{s c}$ the contact force acting on the connector per unit length.

- Equilibrium equations in case of discrete bond

Due to the discrete nature of the shear connection, the stress resultants of the connected layer are discontinuous with "jumps" at each connector location. To derive the equilibrium conditions for a two-layer beam with discrete shear connection, it is necessary to consider separately the equilibrium of an infinitesimal unconnected beam segment and the equilibrium at the cross-section containing shear connectors.

The first set of equilibrium equations, which apply between two consecutive connectors, is readily obtained by expressing the equilibrium of an infinitesimal unconnected two-layer beam segment of length $d x$, and subjected to an external distributed load (see Fig. 4).
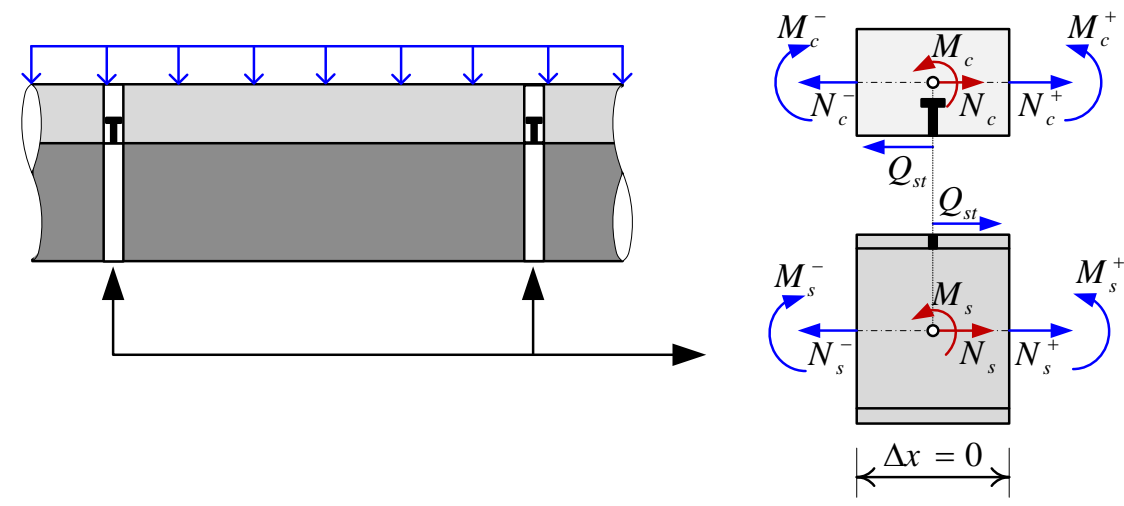

Figure 4. Composite beam segment with discrete bond.

For the composite beam element without connector, the equilibrium conditions can be written in the following form: 
Transport and Communications Science Journal, Vol. 72, Issue 7 (09/2021), 811-823

$$
\begin{aligned}
& \frac{d N_{c}}{d x}=0 \\
& \frac{d N_{s}}{d x}=0 \\
& \frac{d T_{s}}{d x}+V_{s c}=0 \\
& \frac{d^{2} M_{c}}{d x^{2}}+V_{s c}-p_{y}=0 \\
& \frac{d M_{s}}{d x}+T_{s}=0
\end{aligned}
$$

For the connector element, the equilibrium conditions are:

$$
\begin{aligned}
& \Delta N_{c}=N_{c}^{+}-N_{c}^{-}=Q_{s t} \\
& \Delta N_{s}=N_{S}^{+}-N_{S}^{-}=-Q_{s t} \\
& \Delta M_{c}=M_{c}^{+}-M_{c}^{-}=h_{c} Q_{s t} \\
& \Delta M_{s}=M_{S}^{+}-M_{S}^{-}=h_{s} Q_{s t}
\end{aligned}
$$

where $Q_{s t}$ is the discrete bond force.

\subsection{Force-deformation relations}

We adopt a linear stress-strain relationship at the material level and deduce the following constitutive law for the cross-section of each layer:

$$
\begin{aligned}
& N_{i}=\int_{A_{i}} \sigma_{i} d A=E_{i} A_{i} \varepsilon_{i} \\
& T_{s}=\int_{A_{s}} \tau_{s} d A=G_{s} A_{s} \gamma_{s} \\
& M_{i}=-\int_{A_{s}} y \sigma_{i} d A=E_{i} I_{i} k_{i}
\end{aligned}
$$

where $E_{i}, A_{i}, I_{i}(\mathrm{i}=\mathrm{s} ; \mathrm{c})$ are the elastic modulus, the area and the second moment of area of cross-section i, $G_{s}$ is the shear modulus of steel beam.

\section{METHOD OF SOLVING EQUATIONS}

\subsection{Closed-form solution for the distributed bond model}

The relationships introduced in the section 2.1 are now combined to derive the equations governing the behavior of a shear-deformable two-layer composite beam with partial interaction. In particular, differentiating the Eqs. (3, 4), and combining with the relation (23), the following relation is obtained 
Transport and Communications Science Journal, Vol. 72, Issue 7 (09/2021), 811-823

$$
\begin{aligned}
& \partial_{x}^{3} v=\partial_{x} \kappa_{c}=\frac{\partial_{x} M_{c}}{E I_{c}} \\
& \partial_{x}^{2} \theta_{s}=\partial_{x} \kappa_{s}=\frac{\partial_{x} M_{s}}{E I_{s}}
\end{aligned}
$$

By combing the above equations with the Eqs. (2) and (22) we obtain

$$
\frac{\partial_{x}^{2} T_{s}}{G A_{s}}=\frac{\partial_{x} M_{c}}{E I_{c}}-\frac{\partial_{x} M_{s}}{E I_{s}}
$$

Moreover, differentiating Eqs. (8) and (11) then combining and using Eqs. $(7,10)$ lead to.

$$
\frac{\partial_{x}^{2} M_{c}}{E I_{c}}-\frac{\partial_{x}^{2} M_{s}}{E I_{s}}+\frac{V_{s c}}{E I}-\frac{p_{y}}{E I_{c}}-\left(\frac{h_{c}}{E I_{c}}-\frac{h_{s}}{E I_{s}}\right) \partial_{x} D_{s c}=0
$$

Where

$$
\frac{1}{E I}=\frac{1}{E I_{s}}+\frac{1}{E I_{c}}
$$

Furthermore, the equilibrium Eq. 27 is differentiated one more time, after taking the Eq. $(7,10)$ and then combined with the Eq. (28) to provide:

$$
\left(\frac{h_{c}}{E I_{c}}-\frac{h_{s}}{E I_{s}}\right) \partial_{x} D_{s c}=-\frac{p_{y}}{E I_{c}}+\frac{V_{s c}}{E I}-\frac{\partial_{x}^{2} V_{s c}}{G A_{s}}
$$

Differentiating twice the Eqs. $(21,23)$ and then introducing into the Eq. (5) leads to

$$
\frac{\partial_{x}^{2} D_{s c}}{k_{s c}}=\frac{\partial_{x} N_{c}}{E A_{c}}-\frac{\partial_{x} N_{s}}{E A_{s}}+\frac{h_{s} \partial_{x} M_{s}}{E I_{s}}+\frac{h_{c} \partial_{x} M_{c}}{E I_{c}}
$$

By using the equilibrium relationships $(6)$ and $(9)$, differentiating Eqs. $(8,11)$ and using Eqs. $(7,10)$, the above equation can be finally transformed as follows:

$$
\left(\frac{h_{c}}{E I_{c}}-\frac{h_{s}}{E I_{s}}\right) V_{s c}=\frac{h_{c} p_{y}}{E I_{c}}+\left(\frac{1}{E A}+\frac{h_{s}^{2}}{E I_{s}}+\frac{h_{c}^{2}}{E I_{c}}\right) \partial_{x} D_{s c}-\frac{\partial_{x}^{3} D_{s c}}{k_{s c}}
$$

Where

$$
\frac{1}{E A}=\frac{1}{E A_{s}}+\frac{1}{E A_{c}}
$$

Note that the differential Eqs. (30) and (31) involve two unknown variables: the interface shear bond force $D_{s c}$ and the uplift force $V_{s c}$. To solve analytically these equations, we need to consider two cases depending on the value of $\alpha=\frac{h_{c}}{E I_{c}}-\frac{h_{s}}{E I_{s}}$. These variables can be solved analytically. Once the expression for $D_{s c}$ and $V_{s c}$ are determined, the analytical expressions for the remaining mechanical variables can be obtained by using the equilibrium,

\subsection{Closed-form solution for the discrete bond model}


The relationships, equilibrium equations, compatibility equations and constitutive relations introduced in the previous sections can be combined to derive the differential equations that governs the behaviour of the shear-deformable two-layer beam with discrete shear connection. To do so, we consider separately an unconnected two-layer beam segment and a connector element in order to keep the continuous quantities of the variables within each element.

By using the equilibrium relationships $(6,9,8)$ and the compatibility Eqs. $(1,3,4)$ the Eq. (6) can be

$$
\partial_{x}^{3} v=\partial_{x}^{2} \gamma_{s}+\partial_{x}^{2} \theta_{s}=\partial_{x}^{2} \theta_{c}
$$

where the shear deformations $\gamma_{s}$ s and the cross-section rotations $\theta_{i}$ are eliminated using relations (22) and (23) to give:

$$
\partial_{x}^{3} v=\frac{\partial_{x}^{2} T_{s}}{G A_{s}}+\frac{\partial_{x}^{2} M_{s}}{E I_{s}}=\frac{\partial_{x}^{2} M_{c}}{E I_{c}}
$$

The above Eq. (33) is differentiated one more time; then, the equilibrium Eqs. (15) and (16) are used to eliminate the layer bending moments $M_{i}$. Moreover, by using the equilibrium Eq. (14) to eliminate the shear force Ts, one obtains a differential equation involving only the uplift force $V_{s c}$, which is the primary unknown of the problem:

$$
\frac{\partial_{x}^{2} V_{s c}}{G A_{s}}-\frac{V_{s c}}{E I}=-\frac{p_{y}}{E I_{c}}
$$

Where

$$
\frac{1}{E I}=\frac{1}{E I_{s}}+\frac{1}{E I_{c}}
$$

It can be seen that $V_{s c}$ determined through Eq.(35). Once the analytical expression for $V_{s c}$ is determined, the analytical expressions for displacements and the other internal forces can be derived by inserting $V_{s c}$ back into the governing equations.

The Matlab programming is used for solving problems based on the above system of equations.

\section{NUMERICAL EXAMPLES AND DISCUSSIONS}

\subsection{Example 1}

In this example, we use a simply-supported composite beam tested by Aribert et al. [20] was employed. This beam was a part of a series of tests aimed to investigate the effect of partial interaction on the behaviour of composite beams. The geometric characteristics and the material properties of the beam are shown in Fig. 5. The beam has a span length of $5000 \mathrm{~mm}$ and is loaded by a single concentrated force at midspan. The steel section of the beam is IPE 330 reinforced at the bottom by a steel plate of $120 \times 8 \mathrm{~mm}^{2}$. The slab is $800 \mathrm{~mm}$ wide and 100 thick, longitudinally reinforced by 5 steel bars of $14 \mathrm{~mm}$ diameter at the mid-depth. The prediction of the proposed analytical models is compared against the existing well-known 
Newmark's model [14] in which each layer is modelled according to Bernoulli assumptions and is continuously connected.

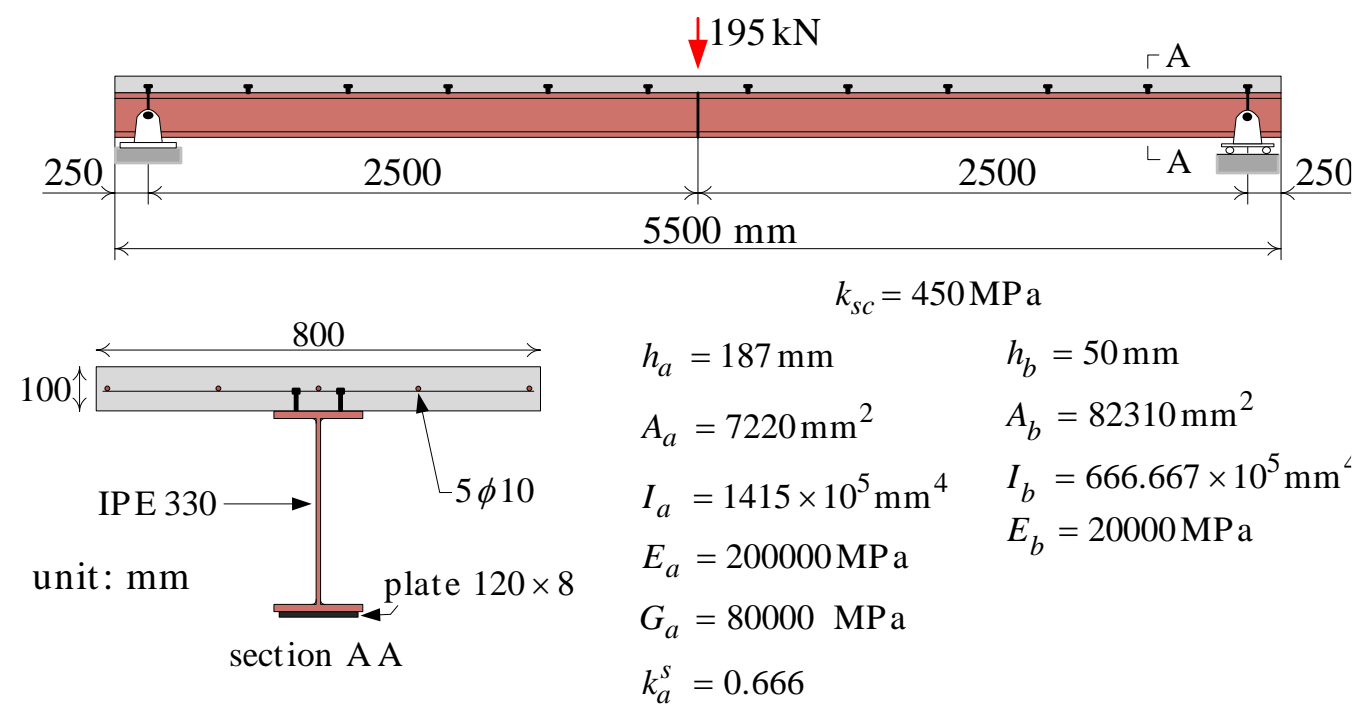

Figure 5. Geometrical and mechanical characteristics of Aribert's beam.

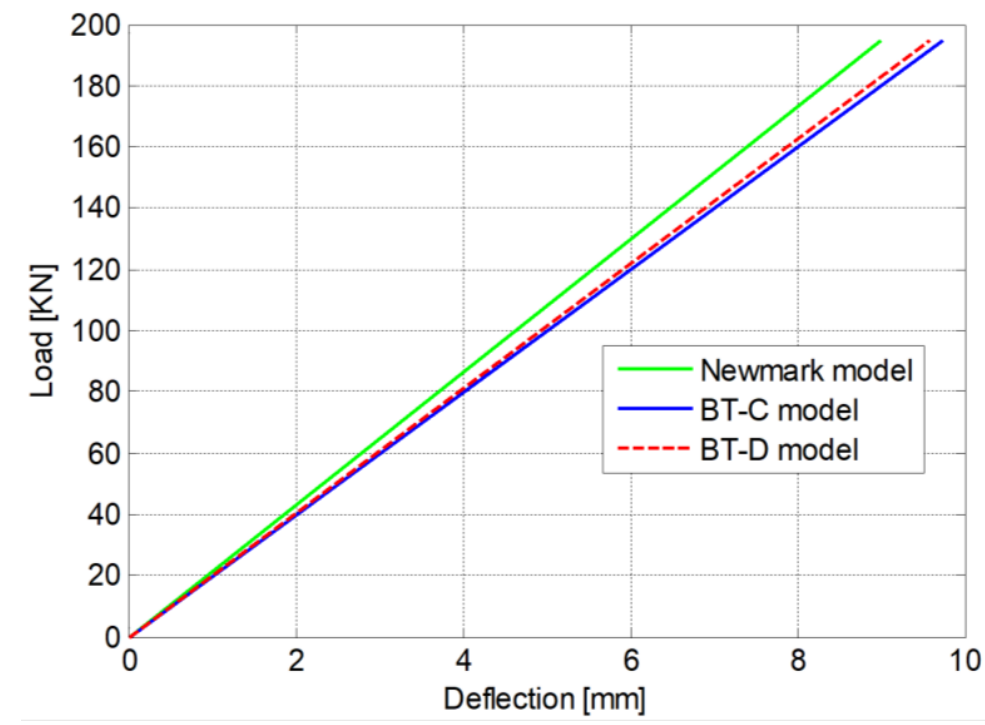

Figure 6. Load-deflection curves.

First, the prediction of the proposed analytical models is compared against the existing well-known Newmark's model [14] in which each layer is modelled according to Bernoulli assumptions and are continuously connected. Next, the influence of the connection model on the structural response of the shear-deformable composite beams was analysed. To do so, the beam was modelled on one hand using four continuous bond beam elements which is the smallest possible number of elements needed for this simulation.

Figure 6 shows the load-deflection curves underneath the load point for Newmark model, distributed bond (BT-C model) and discrete bond (BT-D model). It can be observed that the two analytical responses are different from each other. However, the shear deformability of the steel joist induces a slight reduction of the beam stiffness compared to the one provided by 
the Newmark's model. The Timoshenko beam with continued bond make a different $6,9 \%$ compared to Bernoulli beam while the one with discrete bond make a reduction of $5,8 \%$.

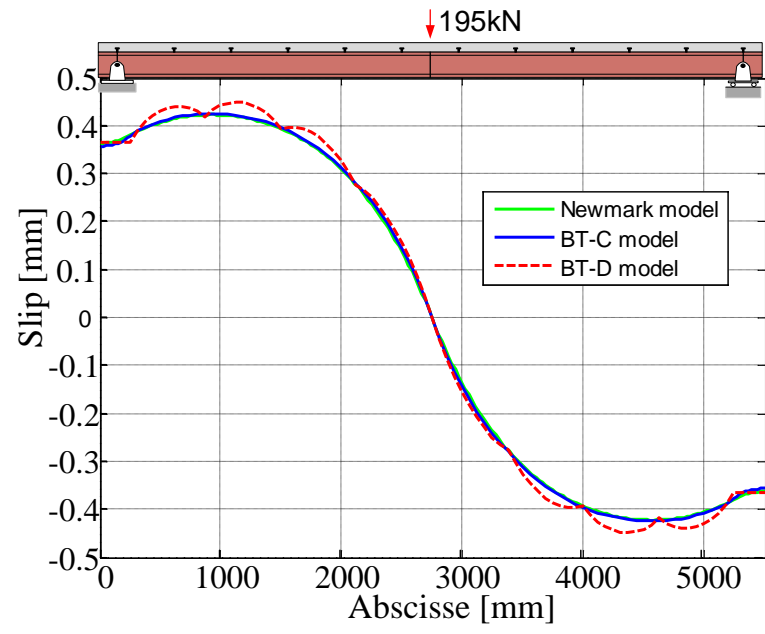

a) Slip distribution along the beam length

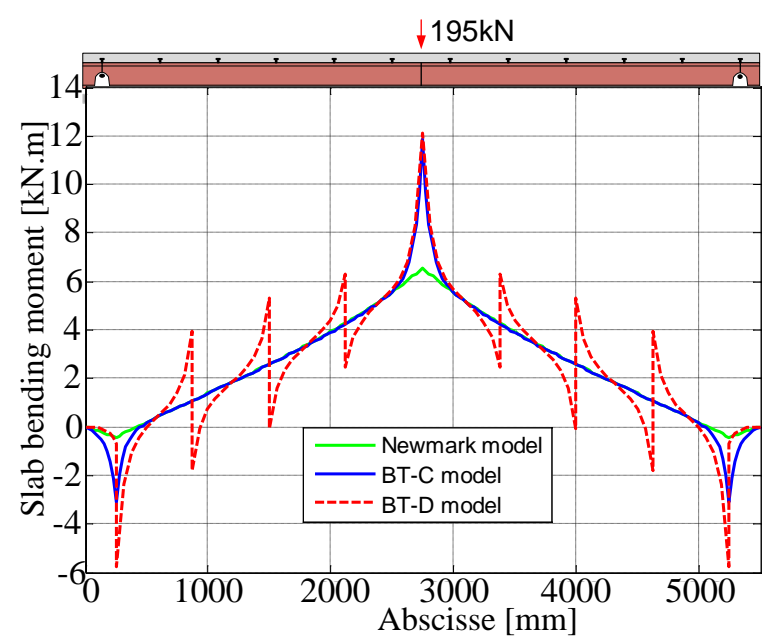

c) Slab bending moment distribution

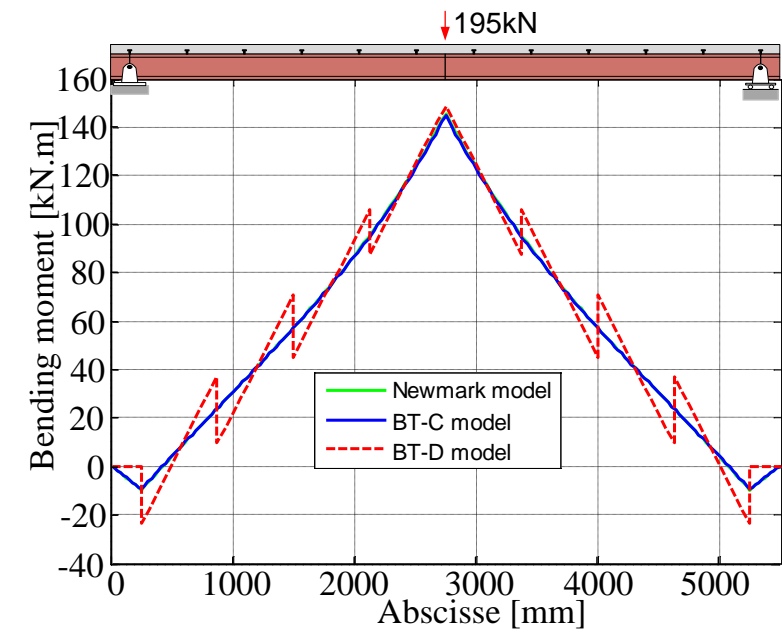

b) Total bending moment distribution

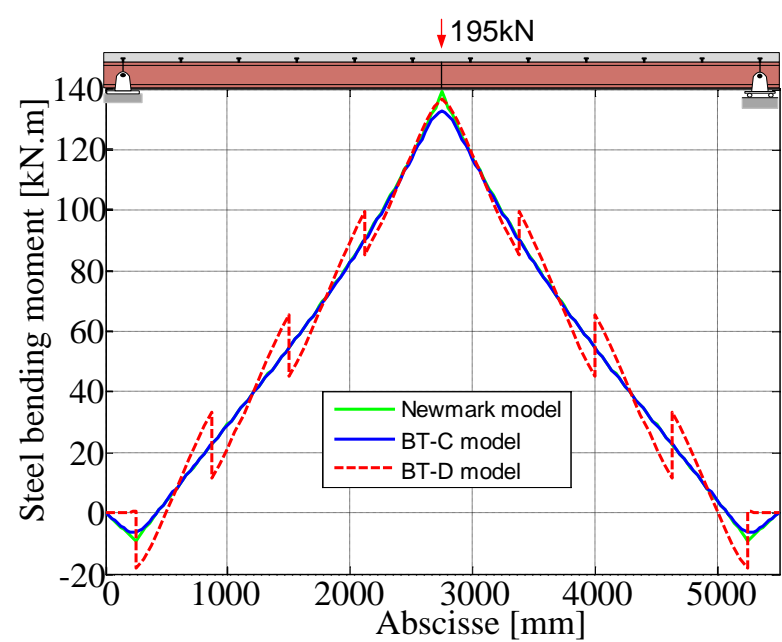

d) Steel bending moment distribution

Figure 7. Slip and bending moment distribution along the beam length.

Figure $7 \mathrm{a}$ shows the slip distribution along the beam length for a value of the concentrated load equal to $195 \mathrm{kN}$. It can be observed that the transverse shear deformation does not significantly affect the slip distribution. Indeed, the slip distribution predicted by the Newmark model almost coincide with the one obtained with the present model with continuous representation of the shear connection. It can be observed that the load-slip curve for the discrete connection model is not smooth at the connector locations. Indeed, the derivative of load-slip curve is discontinuous.

The same phenomena are observed in terms of bending moment distribution for two layers: significant discontinuities under discrete bond (Fig. 7b, c, d). The observed results are not much different compared to the one of Newmark's model but there is a significant gap at the position of supports. This comes from the fact that the bending moment distribution for each layer is discontinuous due to jumps in bond forces as we can see in Eqs (19), (20).. 


\subsection{Example 2}

The calculated bridge is Tien Phong bridge, located in Thuong Tin district, Hanoi city [21]. The bridge structure includes 3 continuous spans using steel-reinforced concrete structure in association with the diagram $(20+24+20) \mathrm{m}$ (see Fig. 8). The high of steel beam and the average thickness of the slab are $1 \mathrm{~m}$ and $0.205 \mathrm{~m}$, respectively. Link connectors are pairs of studs with height $\mathrm{h}=0.12 \mathrm{~m}$, diameter $=0.2 \mathrm{~m}$ and space $=0.3 \mathrm{~m}$.

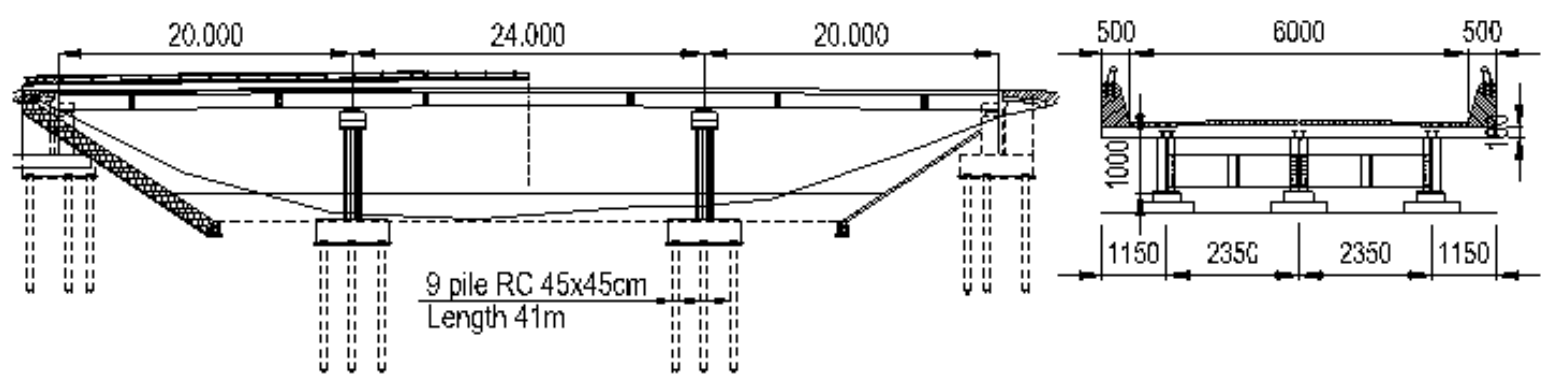

Figure 8. General view of Tien Phong Bridge.

With low traffic volume, the bridge design live load is $0.75 \mathrm{HL}-93$ according to TCVN11823: 2017 bridge design standard (equivalent to AASHTO). The deadload is selfweight, wearing surfaces and utilities.

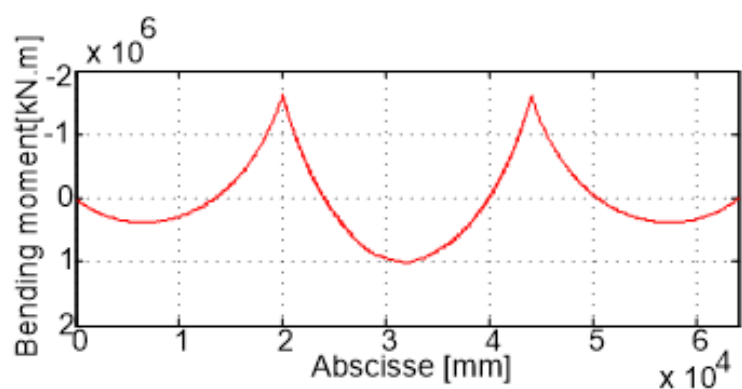

a) Moment

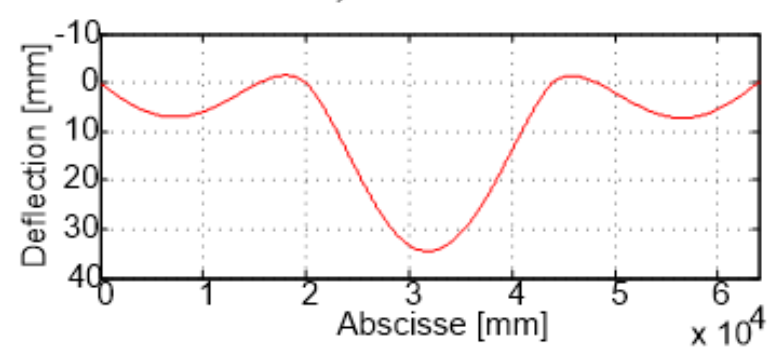

c) Deflection

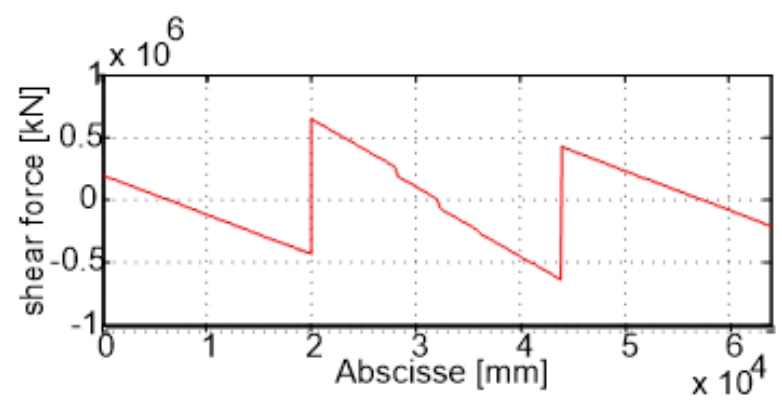

b) Shear

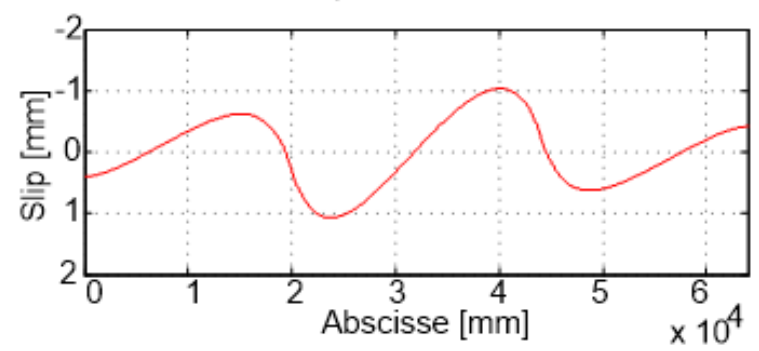

d) Slip

Figure 9. Force and deformation diagrams of composite beam bridges In this section, the discrete bond model is considered. The aim of this section is to examine in more detail the influence of the connection model on the behaviour of continuous beams. The composite girder with point link at the spring position was calculated utilizing the horizontal distribution coefficient. The results of bending moment, shear force, beam deflection and beam shear slip between two material layers, steel beam and concrete slab in the middle of the middle span are given in Fig. 9. 
We can observe that the distribution of bending moment, shear force, deflection and slip totally fit the one of continuous beam. Only a light jump can be noticed at the spring position because the connection is dense. It can be concluded that replacing a continuous connection by a discrete one does not much change the global response. However, with discrete bond model, the number of elements cannot be smaller than the rank number of connectors minus one. In this example, the concrete slab is connected to the steel beam by 215 ranks of two connectors. Therefore 214 is the smallest number of elements we can use in the case of discrete bond. Indeed, the discrete bond model seems to describe the true nature of the connection of the usual composite steel-concrete beams. However, it requires a large number of elements, especially in the case of dense connection. Moreover, when analyzing in detail, it is necessary to use discrete model to calculate connectors.

\section{CONCLUSIONS}

The paper presented a method for calculating beam bridges by using model of interaction between connectors and reinforced concrete slab. The following conclusions can be drawn from the present study.

In the calculation of the associated beam, the model of the discrete point connection at the spring position together with the Timoshenko beam theory considering horizontal shear strain has provided accurate results and accurately reflects the actual performance of the structure. The results were compared with the continuous point alignment and the Newmark model. The compared results with simple beams show the deflection of the beam Timoshenko with continued bond make a different $6.9 \%$ compared to beam Bernoulli while the one with discrete bond makes a reduction of $5.8 \%$.

Using the discrete point connection model at the linked anchor points was made for the continuous span girder, showing the applicability in practical calculation of the structure. Discrete point topology model at connection spring performing for continuous span bridge beams has indicated the applicability in practice of structural calculation.

\section{REFERENCES}

[1]. D. Collings, Steel-concrete Composite Bridges, Thomas Telford, 2005.

[2]. J. Brozzetti, Design development of steel-concrete composite bridges in France, Journal of Constructional Steel Research, 55 (2000) 229-243. https://doi.org/10.1016/S0143-974X(99)00087-5

[3]. J.-S. Fan, Y.-F. Liu, C. Liu, Experiment study and refined modeling of temperature field of steelconcrete composite beam bridges, Engineering Structures, 240 (2021) 112350. https://doi.org/10.1016/j.engstruct.2021.112350

[4]. A. Si Larbi, E. Ferrier, B. Jurkiewiez, P. Hamelin, Static behaviour of steel concrete beam connected by bonding, Engineering Structures, 29 (2007) 1034-1042. https://doi.org/10.1016/j.engstruct.2006.06.015

[5]. R. Rahnavard, C. Rebelo, H.D. Craveiro, R. Napolitano, Understanding the cyclic performance of composite steel-concrete connections on steel bridges, Engineering Structures, 224 (2020) 111213. https://doi.org/10.1016/j.engstruct.2020.111213

[6]. N.E. Shanmugam, B. Lakshmi, State of the art report on steel-concrete composite columns, Journal of Constructional Steel Research, 57 (2001) 1041-1080. https://doi.org/10.1016/S0143974X(01)00021-9

[7]. H. Robinson, K. S. Naraine, Slip and uplift effects in composite beams, In Composite Construction in Steel and Concrete, (1988) 487-497. 
[8]. J. M. Aribert, K. Abdel Aziz, Calculation of composite beams up to ultimate state with the effect of uplift at steel-concrete interface, Revue Construction Metallique, 1985 (1985) 3-36.

[9]. R. P. Johnson, Composite Structures of Steel and Concrete: Beams, Slabs, Columns and Frames for Buildings, John Wiley \& Sons, 2018.

[10].X. Zeng, S.-F. Jiang, D. Zhou, Effect of Shear Connector Layout on the Behavior of SteelConcrete Composite Beams with Interface Slip, Applied Sciences, 9 (2019) 207. https://doi.org/10.3390/app9010207

[11]. J. Nie, Y. Li, Z. Yu, Study on short and long-term rigidity of composite steel-concrete beams, Journal-Tsinghua University, 38 (1998) 38-41.

[12]. T.H. Nguyen, Damage detection in a steel beam structure using a soft sensor and logistic regression, Transport and Communications Science Journal, 69 (2018) 10-24. (In Vietnamese)

[13]. Z. Lai, A.H. Varma, L.G. Griffis, Analysis and Design of Noncompact and Slender CFT BeamColumns, Journal of Structural Engineering, $142 \quad$ (2016) 04015097. https://doi.org/10.1061/(ASCE)ST.1943-541X.0001349

[14]. N.M. Newmark, Test and analysis of composite beams with incomplete interaction, Proceedings of Society for Experimental Stress Analysis, 9 (1951) 75-92.

[15]. J. W. Baldwin, J. R. Henry, C. M. Sweeney, Study of Composite Bridge Stringers, Phase II, University of Missouri, May (1965).

[16]. M.W. Hallam, An analysis of the behaviour of continuous composite beams under repeated loading, (1978). https://trid.trb.org/view/81768

[17]. B. Cas, M. Saje, I. Planinc, Non-linear finite element analysis of composite planar frames with an interlayer slip, Computers \& Structures, 82 (2004) 1901-1912. https://doi.org/10.1016/j.compstruc.2004.03.070

[18]. S. Schnabl, M. Saje, G. Turk, I. Planinc, Locking-free two-layer Timoshenko beam element with interlayer slip, Finite Elements in Analysis and Design, 43 (2007) 705-714. https://doi.org/10.1016/j.finel.2007.03.002

[19]. S. Schnabl, M. Saje, G. Turk, I. Planinc, Analytical Solution of Two-Layer Beam Taking into account Interlayer Slip and Shear Deformation, Journal of Structural Engineering, 133 (2007) 886894. https://doi.org/10.1061/(ASCE)0733-9445(2007)133:6(886)

[20]. J.D. Parameshwar, Seismic response of steel and composite steel joints with semi-continuous connections, M.Phil., Swansea University (United Kingdom). https://www.proquest.com/docview/2040195817/abstract/858A78F08F9E43ADPQ/1

[21]. UCT Co., Ltd, Description and Drawing of Tien Phong 2 Bridge, Hanoi (2017). 